\title{
Administration of crizotinib through gastrostoma resolves esophageal occlusion caused by lymph node metastasis of squamous cell lung cancer with ROS1 fusion gene: a case report
}

\author{
Masayuki Nakayama $^{1)}$, Yoshiaki Nagai ${ }^{1}$, Ayumi Uchiyama $^{1)}$, Tatsuya Saito ${ }^{1)}$, Naoya Iwanami ${ }^{1)}$, \\ Koutarou Hanawa $^{1)}$, Akiko Okuyama ${ }^{1)}$, Teruhiro Sano ${ }^{1)}$, Haruna Sato ${ }^{1)}$, Kenichi Tabata ${ }^{2)}$, \\ Daisuke Matsubara ${ }^{3)}$, Koichi Hagiwara ${ }^{1)}$ \\ ${ }^{1)}$ Division of Pulmonary Medicine, Department of Medicine, Jichi Medical University \\ ${ }^{2)}$ Department of Diagnostic Pathology, Jichi Medical University \\ ${ }^{3)}$ Department of Integrative Pathology, Jichi Medical University
}

\begin{abstract}
ROS1 fusion gene is rarely found in squamous cell lung cancer (SQCLC). We report a patient with SQCLC with ROS1 fusion gene, in which crizotinib administered through gastrostoma achieved a good response. A 77-year-old Japanese woman with no history of smoking underwent right lower lobectomy, and was diagnosed as stage IIA SQCLC. One year later, the disease recurred and her lymph nodes were enlarged by metastasis occluded esophagus. She had difficulty in eating and underwent percutaneous endoscopic gastrostomy. ROS1 fusion gene was detected in a curated surgical specimen. Administration of crizotinib through gastrostoma resolved the occlusion, although the simultaneous administration of a low-dose of prednisolone was required to avoid neutropenia. She was then able to eat through her mouth. She has been on crizotinib therapy for more than one year and has remained symptom-free.
\end{abstract}

Keywords: ROS1 fusion gene, squamous cell lung cancer, crizotinib, gastrostoma, neutropenia.

(Received May 31, 2019; Accepted June 7, 2019)

\section{Introduction}

The administration of ROS1 tyrosine kinase inhibitors has been dramatically improved the treatment of nonsmall cell lung cancer (NSCLC) with ROS1 fusion gene. This fusion gene has been identified in $1 \%-2 \%$ of patients with NSCLC, most of which are adenocarcinoma in young, non-smokers ${ }^{1)}$. In contrast, squamous cell lung cancer (SQCLC) with ROS1 fusion gene is rare. Here, we report a case of squamous cell carcinoma with keratinization. The tumor also had adenocarcinoma component of less than $5 \%$. The esophagus was occluded by metastatic lymph nodes, but it reopened after the administration of crizotinib through gastrostoma. This case shows that crizotinib is effective in ROS1 fusion gene-positive lung cancer with squamous cell carcinoma histology.

Corresponding author: Masayuki Nakayama, MD, PhD. Division of Pulmonary Medicine, Department of Medicine, Jichi Medical University, 3311-1 Yakushiji, Shimotsuke, Tochigi 329-0498, Japan Tel: +81(285)58-7350, Fax: +81(285)443586, E-mail: mnakayama723@jichi.ac.jp

\section{Case}

A 77-year-old woman with no history of smoking was diagnosed as stage IIA lung cancer in the right lower lobe. She underwent lobectomy with lymph node dissection (ND2a-2). Histological analysis indicated SQCLC with keratinization (Fig. 1) and that it contained adenocarcinoma component of less than 5\% (Fig. 2). One year after lobectomy, she complained of dysphagia. Chest computed tomography showed mediastinal lymphadenopathy that suggested recurrence (Fig. 3A). Endoscopic examination revealed esophageal stenosis (Fig. 4A). She had difficulty in eating, and therefore underwent percutaneous endoscopic gastrostomy. A retrospective examination of samples isolated at the time of lobectomy revealed the tumor proportion score (TPS) of PDL1 staining of $75 \%$ and that it was negative for EGFR mutation. Treatment with pembrolizumab was initiated. However, her dysphagia exacerbated and the mediastinal lymph node was enlarged. The treatment was changed to tegafur/gimeracil/oteracil administration through gastrostoma. Three months of treatment did not demonstrate any benefit. The esophagus was completely occluded, her 


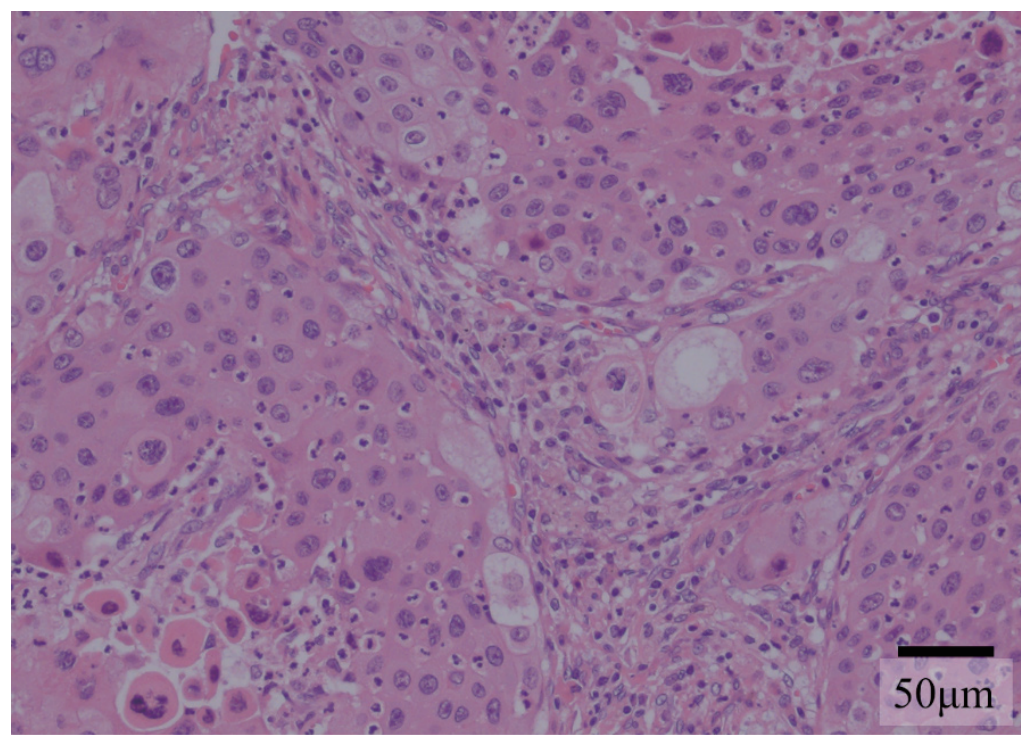

Fig. 1 Historical examination revealed squamous cell carcinoma with keratinization (Hematoxylin Eosin Saffron stain, $\times 200$ )

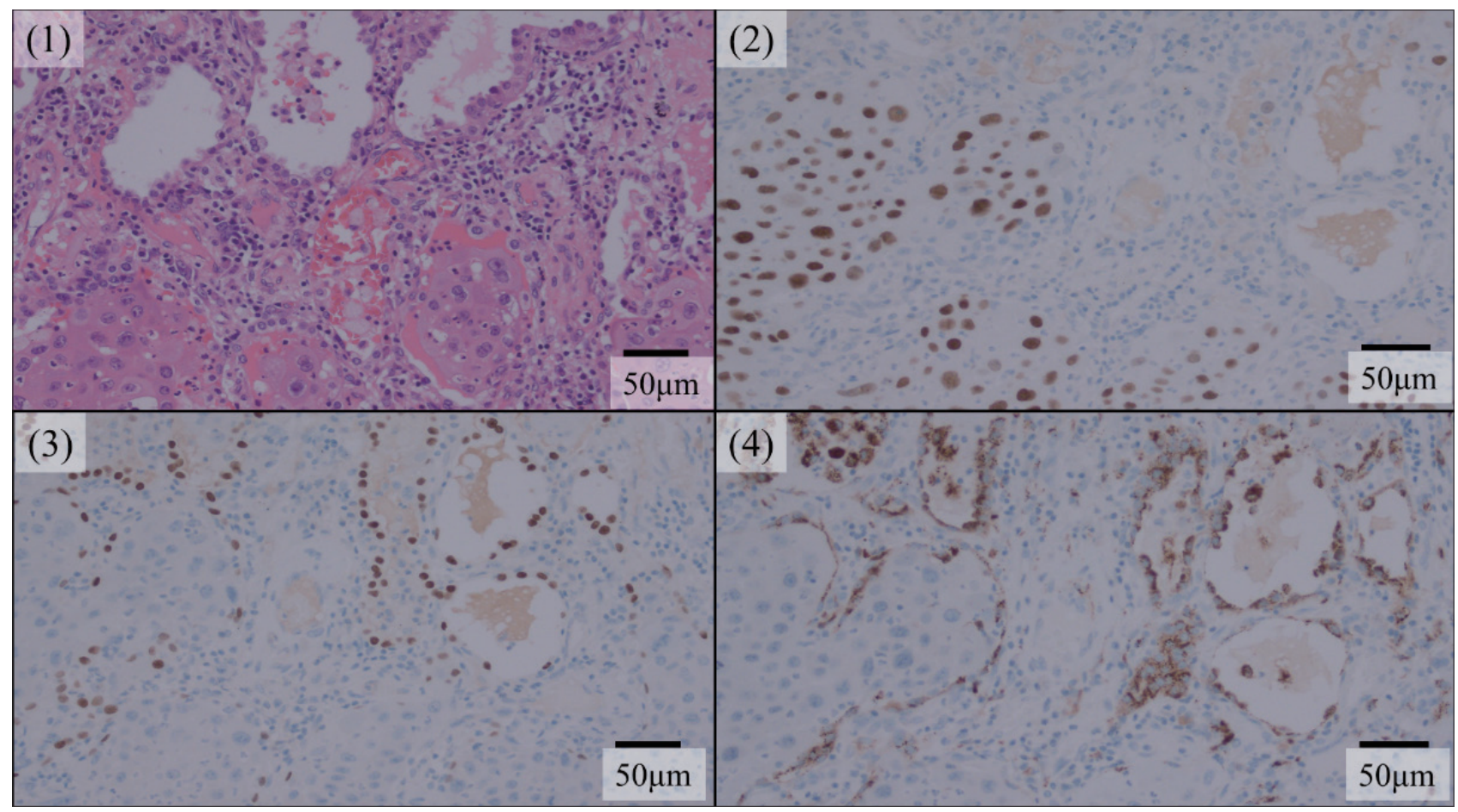

Fig. 2 Squamous cell carcinoma and adenocarcinoma (in less than 5\%) were seen (Hematoxylin Eosin Saffron stain, $\times 200)(1)$, and immunohistochemical analysis demonstrated P40 protein positivity in squamous cell carcinoma (2), and TTF-1 (3) and Napsin A (4) positivity in adenocarcinoma (×200).

body weight decreased from 42 to $32 \mathrm{~kg}$, and her performance status (PS) deteriorated from 1 to 2 . Re-evaluation of the lobectomy sample demonstrated that the cancer cells were positive for ROS1 fusion gene using reverse transcriptase-polymerase chain reaction (RT-PCR) assay. Crizotinib, $400 \mathrm{mg}$ every day, was then administered through gastrostoma. Two weeks later, she developed grade 3 neutropenia according to the Common Toxicity Criteria for Adverse Events. Neutropenia continued with a reduced dose of crizotinib. Simultaneous administration of prednisolone, $10 \mathrm{mg}$ per day, circumvented neutropenia. After two months of treatment, the size of the mediastinal lymph node became smaller (Fig. 3B), and the esophagus re-opened (Fig. 4B). She began to eat. She has been on crizotinib treatment for more than one year and is symptom-free with a PS 0 . 


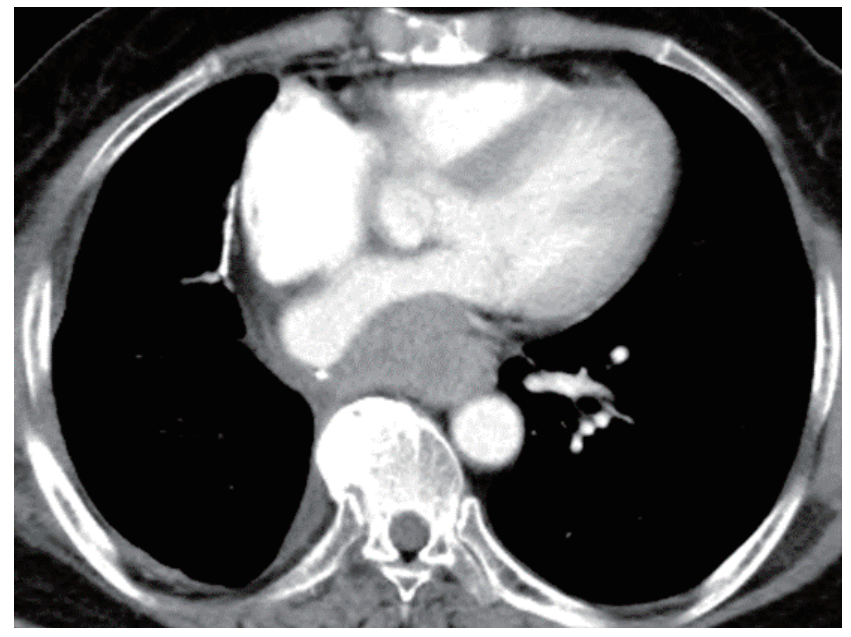

(A)

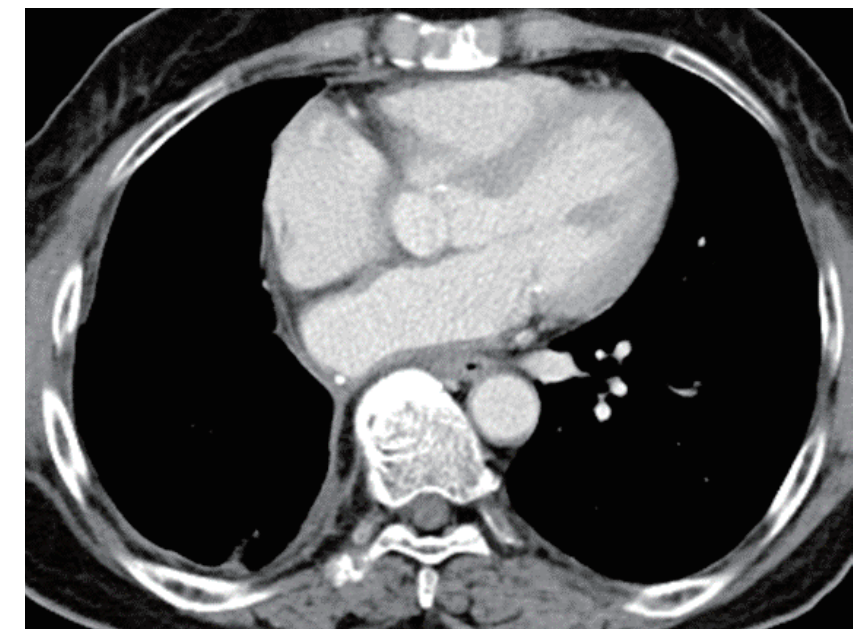

(B)

Fig. 3 Chest computed tomography shows mediastinal lymphadenopathy with a displaced esophagus at the time of recurrence (A). The lymph nodes shrank six months after initiating crizotinib (B).

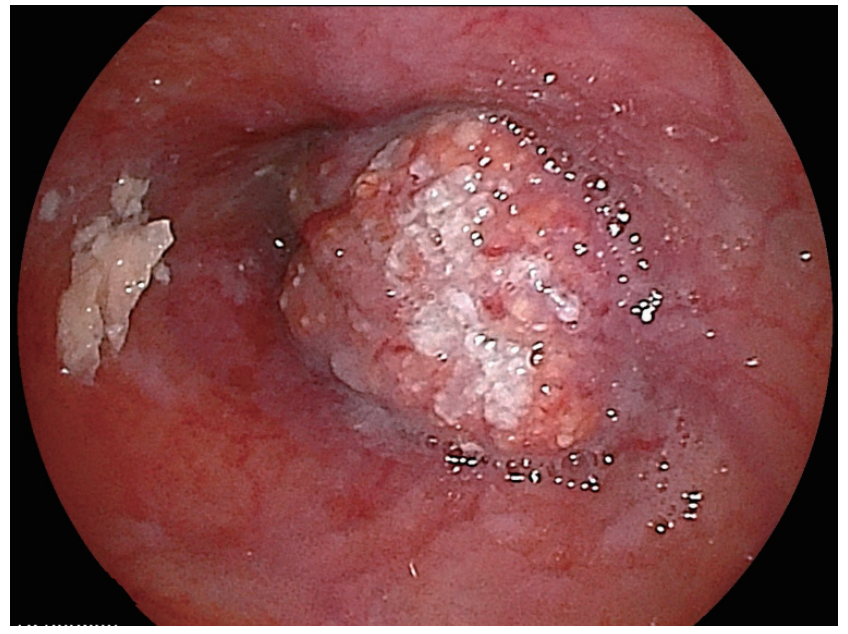

(A)

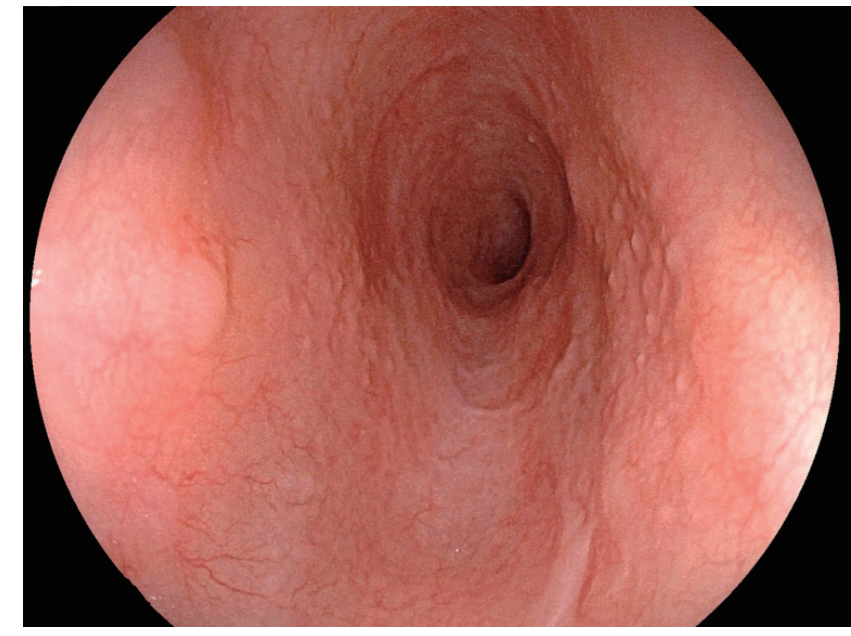

(B)

Fig. 4 Upper digestive tract endoscopy shows an occlusion in the middle esophagus (A). The occlusion was resolved after the administration of crizotinib (B).

\section{Discussion}

We report a patient with SQCLC harboring ROS1 fusion gene. The tumor responded to crizotinib suggesting that tumors with SQCLC histology may depend on signaling from ROS1 fusion gene.

ROS1 fusion gene is detected in $1.7 \%$ of NSCLC, mostly in adenocarcinoma; however, this gene is rarely found in SQCLC ${ }^{1)}$. Of 6,066 patients with pathologically confirmed NSCLC, ROS1 fusion gene was detected in $2.6 \%$ cases (adenocarcinoma $2.2 \%$ and squamous carcinoma $0.07 \%)^{2}$. Accordingly, the current National Comprehensive Cancer Network guideline recommends that molecular screening focuses on lung adenocarcinoma.

Molecular profiling of SQCLC has suggested that many SQCLCs may not depend on a single oncogenic driver gene. In our patient, most of the tumor was squamous cell carcinoma with keratinization and adenocarcinoma content was less than $5 \%$. Crizotinib shrank the tumor more than the content of adenocarcinoma, suggesting that the portion of tumor with SQCLC histology depended on signaling from the fusion gene. This case suggests that even patients with SQCLC may benefit from molecular diagnosis for oncogenic driver genes.

Administration of cytotoxic antitumor reagents are not recommended for patients with a poor PS. In contrast, tyrosine kinase inhibitors may be administered even to the patients with PS4 by a variety of routes ${ }^{3)}$. There have been two reports on the administration of tyrosine kinase inhibitors through gastrostoma: gefitinib for a patient with EGFR mutation ${ }^{4}$, and crizotinib for a patient with ALK fusion gene ${ }^{5)}$. In these reports, the drugs were ad- 
ministered after being dissolved in warm water. We also dissolved crizotinib in warm water and then administered it through gastrostoma, simulating oral administration. As expected, no complications were observed. We think this type of administration was allowed because the situation demanded it.

Severe neutropenia has been reported in $10 \%$ of patients who received crizotinib treatment ${ }^{6,7)}$. It was suggested that crizotinib elicits neutropenia through an immune-mediated response ${ }^{8)}$ or by inhibiting the c-Met receptor ${ }^{9)}$. Immune-mediated neutropenia often occurs within a few weeks, and low-dose prednisolone may be an effective treatment for $\mathrm{it}^{10)}$. Therefore, we simultaneously administered prednisolone and found it was effective for neutropenia.

Here we report a patient with SQCLC with ROS1 fusion gene. Although she had a poor PS, administration of crizotinib through the gastrostoma was effective. Our case demonstrates the importance of molecular diagnosis when selecting an effective treatment for SQCLC.

\section{Conflict of interest:}

Koichi Hagiwara has received lecture's fee from Pfizer Japan Inc. unrelated to this work.

\section{References}

1) Bergethon K, Shaw AT, Ou SH, Katayama R, Lovly CM, McDonald NT, Massion PP, Siwak-Tapp C, Gonzalez A, Fang R, Mark EJ, Batten JM, Chen H, Wilner KD, Kwak EL, Clark JW, Carbone DP, Ji H, Engelman JA, Mino-Kenudson M, Pao W, Iafrate AJ. (2012) ROS1 rearrangements define a unique molecular class of lung cancers. J Clin Oncol. 30: 863-870.

2) Zhang Q, Wu C, Ding W, Zhang Z, Qiu X, Mu D, Zhang H, Xi Y, Zhou J, Ma L, Fu S, Gao M, Wang B, Deng J, Lin D, Zhang J. (2019) Prevalence of ROS1 fusion in Chinese patients with non-small cell lung cancer. Thorac Cancer. 10: 47-53.

3) Inoue A, Kobayashi K, Usui K, Maemondo M, Okinaga S, Mikami I, Ando M, Yamazaki K, Saijo Y, Gemma A, Miyazawa H, Tanaka T, Ikebuchi K, Nukiwa T, Morita S, Hagiwara K; North East Japan Gefitinib Study Group. (2009) First-line gefitinib for patients with advanced non-small-cell lung cancer harboring epidermal growth factor receptor mutations without indication for chemotherapy. J Clin Oncol. 27: 1394-1400.
4) Suzumura T, Yonesaka K, Tsukuda H, Fukuoka M. (2014) Successful gefitinib treatment administration via gastrostomy tube in a patient with non-small cell lung cancer with dysphagia. BMJ Case Rep. 13; 2014. pii: bcr2013202705. doi: 10.1136/bcr-2013202705

5) Tamai $K$, Nagata K, Otsuka K, Nakagawa A, Tachikawa R, Otsuka K, Katakami N, Tomii K. (2013) Crizotinib administered via nasogastric and percutaneous endoscopic gastrostomy tubes for the successful treatment of ALK-rearranged lung cancer in a patient with poor performance status. Respir Investig. 51: 46-48.

6) Camidge DR, Bang YJ, Kwak EL, Iafrate AJ, Varella-Garcia M, Fox SB, Riely GJ, Solomon B, Ou SH, Kim DW, Salgia R, Fidias P, Engelman JA, Gandhi L, Jänne PA, Costa DB, Shapiro GI, Lorusso P, Ruffner K, Stephenson P, Tang Y, Wilner K, Clark JW, Shaw AT. (2012) Activity and safety of crizotinib in patients with ALKpositive non-small-cell lung cancer: updated results from a phase 1 study. Lancet Oncol. 13: 1011-1019.

7) Shaw AT, Kim DW, Nakagawa K, Seto T, Crinó L, Ahn MJ, De Pas T, Besse B, Solomon BJ, Blackhall F, Wu YL, Thomas M, O'Byrne KJ, Moro-Sibilot D, Camidge DR, Mok T, Hirsh V, Riely GJ, Iyer S, Tassell V, Polli A, Wilner KD, Jänne PA. (2013) Crizotinib versus chemotherapy in advanced ALK-positive lung cancer. N Engl J Med. 368: 2385-2394.

8) Pontikoglou C, Papadaki HA. (2010) Idiosyncratic drug-induced agranulocytosis: the paradigm of deferiprone. Hemoglobin. 34 : 291-304.

9) Santoro A, Rimassa L, Borbath I, Daniele B, Salvagni S, Van Laethem JL, Van Vlierberghe H, Trojan J, Kolligs FT, Weiss A, Miles S, Gasbarrini A, Lencioni M, Cicalese L, Sherman M, Gridelli C, Buggisch P, Gerken G, Schmid RM, Boni C, Personeni N, Hassoun Z, Abbadessa G, Schwartz B, Von Roemeling R, Lamar ME, Chen Y, Porta C. (2013) Tivantinib for second-line treatment of advanced hepatocellular carcinoma: a randomised, placebocontrolled phase 2 study. Lancet Oncol. 14: 55-63.

10) Toyota Y, Sakugawa M, Bessho A, Horiuchi T, Hosokawa S, Watanabe Y. (2014) Therapeutic Use of Low-dose Corticosteroids to Treat Neutropenia Resulting from Crizotinib Administration in a Patient with Anaplastic Lymphoma Kinase Gene Translocationpositive Lung Cancer. Japanese Journal of Lung Cancer. 54: 78-83. (In Japanese) 